\title{
MANIFESTAÇÕES INTERPRETATIVAS DE LICENCIANDOS EM QUÍMICA SOBRE CONTEXTUALIZAÇÃO NO ENSINO DE CIÊNCIA, TECNOLOGIA E SOCIEDADE (CTS)
}

\author{
Éverton da Paz Santos 1 \\ Marlene Rios Melo ${ }^{2}$
}

\begin{abstract}
RESUMO
Este trabalho se propõe a investigar as manifestações interpretativas, de um grupo de licenciandos em Química, de uma universidade pública do Nordeste, sobre contextualização crítica na perspectiva educacional CTS, a partir de uma leitura de referenciais teóricos que se comprometem com esta abordagem. Além disso, avaliar o entendimento dos licenciandos a partir de uma produção textual diante das concepções manifestadas e dos discursos escritos, apoiados na Análise Textual Discursiva. Para tanto, foram selecionados dois artigos que se complementavam, tendo o mesmo autor principal. Após as leituras dos artigos, os licenciandos produziram um texto sobre a contextualização diante das compreensões deles sobre a perspectiva de ensino CTS. Os resultados obtidos possibilitaram a criação de categorias, por meio das manifestações discursivas dos licenciandos, sendo possível enquadrar e categorizar estes discursos. É importante destacar que as interpretações apontadas e levantadas estão diretamente relacionadas à formação profissional e familiar destes futuros professores, independente se a prática da leitura e escrita é valorizada ou não na universidade.
\end{abstract}

Palavras-chave: Contextualização. CTS. Formação de Professores. Análise Textual Discursiva.

\section{INTERPRETATIVE MANIFESTATIONS OF CHEMISTRY STUDENTS ON CONTEXTUALIZATION IN SCIENCE, TECHNOLOGY AND SOCIETY TEACHING (STS)}

\begin{abstract}
This paper aims to investigate the interpretative manifestations of a group of chemistry students of a public university of the Northeast about critical contextualization in the educational perspective STS from a reading of theoretical references that are committed to this approach. In addition, evaluate the

\footnotetext{
1 Mestre em Ensino de Ciências Naturais e Matemática (UFS). Licenciado em Química pela Faculdade Pio Décimo (FPD). Professor de Educação Profissional na Escola Senai "Luiz Pagliato". Sorocaba, São Paulo, Brasil. Orcid iD: https://orcid.org/0000-0002-2078-2623. E-mail: eda-paz@hotmail.com

2 Doutora em Educação (USP). Mestre em Química Inorgânica (Unicamp). Bacharel em Química Tecnológica (USP). Licenciada em Química (Faculdade Oswaldo Cruz-SP).

Professora associada da Universidade Federal do Rio Grande (FURG). Professora colaboradora do Programa de Pós-Graduação em Educação em Ciências, Química para a Vida e Saúde. São Lourenço do Sul, Rio Grande do Sul, Brasil. Orcid iD:

https://orcid.org/0000-0002-0918-784X.E-mail: marlenemelo@terra.com.br
}

Revista Exitus, Santarém/PA, Vol. 10, p. 01-26, e020103, 2020. 
understanding of those students from a textual production in the face of manifested conceptions and written discourses supported by Discursive Textual Analysis. Therefore, two complementary articles were selected with the same main author. After reading the articles, the students will produce a text about the contextualization before the comprehension about the perspective of STS teaching. The selected results allow the creation of categories through the discursive manifestations of the students being possible to frame and categorize these discourses. It is important to highlight that the interpretations pointed out and raised are directly related to the professional and family education of these new teachers, regardless of the reading and writing practice valued or not at the university.

Keywords: Contextualization. STS. Teacher education. Discursive textual analysis.

\section{MANIFESTACIONES INTERPRETATIVAS DE LOS LICENCIADOS EN QUÍMICA SOBRE LA CONTEXTUALIZACIÓN EN LA ENSEÑANZA DE CIENCIA, TECNOLOGÍA Y SOCIEDAD (CTS)}

\section{RESUMEN}

Este trabajo tiene como objetivo investigar las manifestaciones interpretativas de un grupo de graduados en química de una universidad pública en el noreste, sobre la contextualización crítica en la perspectiva educativa CTS, basada en una lectura de referencias teóricas que están comprometidas con este enfoque. Además, evaluar la comprensión de los licenciantes a partir de una producción textual en vista de las concepciones manifestadas y discursos escritos, apoyados por el análisis textual discursivo. Se seleccionaron dos artículos que se complementaban entre sí, con el mismo autor principal. Después de leer los artículos, los licenciantes produjeron un texto sobre contextualización en vista de sus entendimientos sobre la perspectiva de la enseñanza de la CTS. Los resultados obtenidos permitieron la creación de categorías, a través de las manifestaciones discursivas de los licenciantes, siendo posibles enmarcar y categorizar estos discursos. Es importante destacar que las interpretaciones señaladas y planteadas están directamente relacionadas con la educación profesional y familiar de estos futuros profesores, independientemente de si la práctica de la lectura y la escritura es valorada o no en la universidad.

Palabras clave: contextualización. CTS. Formación del Profesorado. Análisis textual discursivo.

\section{INTRODUÇÃO}

De acordo com o dicionário eletrônico Aurélio $^{3}$ da Língua Portuguesa, a palavra contexto, significa $o$ que se constitui no seu todo, uma composição, um conjunto de uma totalidade; um argumento diante do

\footnotetext{
${ }^{3}$ O Novo Dicionário Aurélio da Língua Portuguesa corresponde à $3^{a}$ edição, $1^{a}$ impressão da Editora Positivo, revista e atualizada do Aurélio Século XXI, O Dicionário da Língua Portuguesa, contendo 435 mil verbetes, locuções e definições.
} 
ambiente. Partindo dessa definição, observamos que várias interpretações podem emergir a partir da utilização frequente do uso do termo.

No entendimento de Machado (2005), do ponto de vista etimológico, a palavra contextuar significa estar enraizado ou fundamentado a um texto, considerando a sua origem e valores culturais que são apreendidos durante a vida. Contextuar, nesse sentido, pode ser definido como um significado enraizado, dotado de valores e relações existentes frente a um contexto ou uma realidade vivida. No sentido em que aqui se utiliza, contextuar é uma estratégia fundamental para a construção de significações. À medida que incorpora relações tacitamente percebidas, a contextualização.

Na visão de Silva (2007), a contextualização é entendida como a relação existente entre o que o aluno sabe, ou seja, as concepções prévias e a sua relação com o contexto e o conteúdo a ser estudado, de modo que possa transformar a sua realidade:

[...] a contextualização no ensino de Ciências que privilegia o estudo de contextos sociais com aspectos políticos, econômicos e ambientais, fundamentado em conhecimentos das ciências e tecnologia, é fundamental para desenvolver um ensino que venha a contribuir para a formação de um aluno crítico, atuante e, sempre que possível, transformador de sua realidade desfavorável. (SILVA; MARCONDES, 2010 p.105).

Considerando este aspecto, é importante que o aluno entenda, de forma clara e objetiva, o que é ensinado em sala de aula, durante a sua formação básica, de modo que possa relacionar o que é ensinado com a sua vida fora do ambiente escolar. Além disso, possa compreender situações específicas no ambiente que o cerca na condição de cidadão.

Os documentos oficiais, tais como os Parâmetros Curriculares Nacionais para o Ensino Médio ( $\mathrm{PCN}$ e PCN+), orientam os professores no que tange a abordagem dos conteúdos através de temas que propiciem uma contextualização do conhecimento químico:

Os conteúdos nessa fase devem ser abordados a partir de temas que permitam a contextualização do conhecimento. Nesse sentido, podem ser explorados, por exemplo, temas como metalurgia, solos e sua fertilização, combustíveis e combustão, obtenção, conservação 
e uso dos alimentos, chuva ácida, tratamento de água etc. Não se pretende que esses temas sejam esgotados, mesmo porque as interrelações conceituais e fatuais podem ser muitas e complexas. Esses temas, mais do que fontes desencadeadoras de conhecimentos específicos, devem ser vistos como instrumentos para uma primeira leitura integrada do mundo com as lentes da Química. (BRASIL, 1999, p. 34).

Ainda nessa perspectiva, é notável a contextualização como eixo fundamental no processo de ensino e aprendizagem, sobretudo, na abordagem dos conteúdos relacionados às ciências da natureza e suas tecnologias envolvendo questões que valorizem o desenvolvimento social, político, econômico, tecnológico e cultural dentro da sociedade. De acordo com OS PCNEM:

O aprendizado de Química no ensino médio [...] deve possibilitar ao aluno a compreensão tanto dos processos químicos em si, quanto da construção de um conhecimento científico em estreita relação com as aplicações tecnológicas e suas implicações ambientais, sociais, políticas e econômicas. Dessa forma, os estudantes podem [...] julgar com fundamentos, as informações advindas da tradição cultural, da mídia e da própria escola e tomar decisões autonomamente, enquanto indivíduos e cidadãos (BRASIL, 1999, p. 86).

Observa-se, destacadamente, que os termos, vivência e fatos do dia a dia, aparecem nos PCNEM, como ponto de partida para abordagem de temas e da construção do conhecimento químico. Ainda nessa perspectiva, em 2006, as Orientações Curriculares para o Ensino Médio (OCEM) foram publicadas com o objetivo de contribuir com a utilização de temas sociais no ensino de ciências e sua relação com as aplicações tecnológicas, sobretudo o contexto real do indivíduo.

Defende-se uma abordagem de temas sociais (do cotidiano) e uma experimentação que, não dissociados da teoria, não sejam pretensos ou meros elementos de motivação ou de ilustração, mas efetivas possibilidades de contextualização dos conhecimentos químicos, tornando-os socialmente mais relevantes [...] (BRASIL, 2006, p. 117).

A atenção dos professores dada aos documentos oficiais, na maioria das vezes, é o enfoque nos temas sociais que estão presentes no cotidiano dos alunos e, sem dúvida, é uma abertura primordial para uma interpretação polissêmica do conceito contextualização, sendo este mais valorizado na 
atuação dos professores em sala de aula, apresentando, portanto, possibilidades para mediar aulas assim, como uma mera ilustração diante da realização de suas atividades, buscando motivar os alunos de alguma forma.

Entretanto, as considerações da comunidade científica e acadêmica em relação a esses documentos são subjetivas e mal interpretadas, conforme discutem Ricardo e Zylbersztajn (2007, p. 340), "pouco se conhece sobre o que pensam e como agem, com relação aos PCN e PCN+, os profissionais que trabalham com a formação inicial de professores nos cursos de licenciatura", em especial, nas disciplinas voltadas para a formação didático-pedagógica. É exatamente o entendimento do que aprender e do que ensinar diante do que é proposto nos documentos, que tem sido o alvo de grandes discussões em pesquisas e no ensino de forma geral, não só no ensino de ciências, mas de outras áreas que contribuem no processo coletivo da construção do conhecimento científico.

Uma forma de entender situações reais envolvidas no ensino de química e em áreas afins, é que se façam leituras, interpretações e posicionamentos diante da realidade vivida, uma vez que, a leitura é um processo de obtenção de informação e incorporação de ideias e teorias, que apresentam diferentes interpretações diante o que se lê. Infere-se que a partir do momento que o licenciando entende $e$ interpreta $\circ$ que lê, busca escrever as suas compreensões e expõe o que sabe ou entende sobre aquilo que se lê, e essa leitura deve ser entendida com uma visão de mundo.

Dessa forma, buscamos estabelecer mediações de leituras de artigos com a finalidade de estudar e compreender o conceito de contextualização numa perspectiva defendida por Santos (2007), estimular aos licenciandos para uma leitura crítica e interagir com um texto lido, de modo que possam se colocar diante do texto, promovendo um momento de leitura que transcende recortes e comentários pessoais.

A partir dessas reflexões e apontamentos, chegamos às seguintes questões da pesquisa: Que interpretações são manifestadas por licenciandos em química, frente à leitura de dois textos que discutem a contextualização na perspectiva de ensino com enfoque CTS?

Revista Exitus, Santarém/PA, Vol. 10, p. 01-26, e020103, 2020. 
Assim, este trabalho tem como objetivo investigar as manifestações interpretativas de um grupo de licenciandos em Química, de uma Universidade Federal do Nordeste, sobre contextualização numa perspectiva de ensino CTS. Primeiramente, a partir de uma leitura de referenciais que se comprometem com esta abordagem, sobretudo, "avaliar o que ficou" destas leituras fundamentadas em análise textual discursiva, presentes na produção escrita dos licenciandos.

\section{CONTEXTUALIZAÇÃO: Conceito e implicações no ensino de ciências}

É evidente a existência de problemas relacionados com a descontextualização no ensino, tanto para os professores que enfrentam cenários distintos em sala de aula, quanto para os alunos, que buscam entender o que é ensinado na escola e tentam relacionar com a sua vida cotidiana. Observa-se que tanto alunos quanto professores, apresentam uma visão simplista do que é contextualização e apontam dificuldades de aprendizagem nos conteúdos específicos, principalmente na área de ciências naturais e matemática. Lopes (2002) discute contextualização no discurso curricular híbrido presente nos Parâmetros Curriculares Nacionais para ○ Ensino Médio e a sua relação com a inserção social no mundo produtivo, e defende a ideia de que esse discurso apresenta ambiguidades e a postura crítica envolvidas nestes parâmetros frente aos diferentes grupos sociais.

Ricardo (2005) aponta uma análise crítica sobre as relações das competências interdisciplinares e contextualização, presentes nos documentos DCNEM, PCN e PCN+. O autor discute que há diferentes entendimentos sobre a contextualização de acordo com os professores formadores e autores responsáveis pela elaboração desses documentos, concluindo que, o termo contextualização é polissêmico, visto que é dotado de concepções distintas, conforme é colocado pelos elaboradores dos documentos.

Sabe-se, no entanto, que nem sempre esta discussão chega à sala de aula, visto que, a polissemia do conceito contextualização propicia um espaço para o professor utilizar a proposta de maneira que lhe faça melhor sentido, em 
diferentes temas de forma superficial, ao invés de fomentar esta discussão com os alunos. É importante que os professores apliquem o conceito de forma clara e objetiva, que faça sentido primeiramente para o aluno, de modo que o contexto do estudante seja valorizado, ou seja, as condições de trabalho, os problemas de saúde enfrentados na sociedade, as questões ambientais e sociais.

Com o objetivo de identificar aplicação efetiva de um projeto político pedagógico de uma escola, no tocante a construção do processo de ensino e aprendizagem de forma contextualizada, Ferreira e Júnior (2020, p. 22) chegaram as seguintes observações:

[...] o PPP com sua lógica do plano de formação dos estudantes possibilita um processo de ensino-aprendizagem contextualizado contribuindo para a formação de um cidadão crítico-reflexivo. Essa lógica do Plano de Formação do PPP do CEFFA M. M. vai ao encontro dos PCNs, que destacam a importância do aluno aprender a mobilizar competências para solucionar problemas em contextos apropriados, sendo capaz de transferir essa capacidade de resolução de problemas para os contextos do mundo social, apresentando um posicionamento crítico-reflexivo, responsável e construtivo, utilizando o diálogo como instrumento para a resolução de conflitos em decisões coletivas.

Os autores apontam, mesmo que o professor conheça a realidade do aluno, não é garantia que ocorra um processo de ensino-aprendizagem contextualizado. E reforçam que o processo de contextualização do ensino é uma abordagem fundamental para a significação dos conteúdos, tornando a aprendizagem mais significativa. Ou seja, é preciso que este projeto, seja mais do que um simples documento escrito com objetivos e metas a serem cumpridas pela comunidade escolar. Ele precisa ser a própria vivência cotidiana da escola. (FERREIRA; JÚNIOR, 2020, p. 22).

Para Costa-Beber e Maldaner (2011), a contextualização é fundamental no cenário educacional escolar, a fim de que os alunos possam agir de forma consciente no mundo, conforme a seguir:

A contextualização do ensino é defendida como princípio organizativo de currículo para melhorar o cenário educacional, por facilitar o desenvolvimento de competências gerais e específicas junto aos estudantes. $\mathrm{O}$ desenvolvimento de determinadas competências básicas 
é considerado essencial para formar as novas gerações mais capacitadas para que possam pensar e agir num mundo sempre mais complexo que Ihes é apresentado, constituindo cidadãos mais conscientes e responsáveis. (COSTA-BEBER; MALDANER; 2011 p.2).

Wartha e Alário (2005) discutiram a contextualização através do livro didático e consideram que a contextualização deve levar em consideração a realidade do aluno, pois:

Contextualizar o conhecimento no seu próprio processo de produção é criar condições para que o aluno experimente a curiosidade, o encantamento da descoberta e a satisfação de construir o conhecimento com autonomia, construir uma visão de mundo e um projeto com identidade própria. (WARTHA; ALÁRIO, 2005, p.44).

Para os autores a autonomia é considerada relevante, uma vez que o aluno deve ser estimulado a formular questões e refletir sobre o mundo a partir do seu ambiente, o qual faz parte da construção da sua própria identidade. Acreditamos que contextualização deve ocorrer através de temas sociais. Wartha e Alário (2005), ao buscarem estes temas em livros didáticos, consideram ainda que a contextualização no ensino acontece quando existe uma relação entre sujeito e objeto, através da incorporação de valores e vivências concretas a todo instante, promovendo o surgimento de novas vivências, não apenas exemplificando as situações de ensino, conforme pode ser visto na afirmação a seguir:

Acreditamos que a contextualização deva centrar-se na abordagem de temas sociais, onde são trabalhadas a integração entre os conceitos científicos e a discussão dos aspectos sociais para que o estudante entenda o contexto em que está inserido e, por sua vez, exigindo deste, um posicionamento crítico quanto à sua solução. (WARTHA; ALÁRIO, 2005, p.46).

Os autores concluem em seu trabalho que, não foram identificadas nos livros didáticos, o uso de terminologias que abordassem o conteúdo químico a partir de questões sociais, ambientais, tecnológicas e econômicas e que tratassem os valores éticos, sobretudo, situações que proporcionassem ao estudante uma tomada de decisão mediante a sua leitura.

Contribuindo com esse entendimento, Silva, Melo e Macedo Arguelho (2020) discutiram possibilidade e limitações do tema social artesanato, como 
proposta de ensino de Ciências, especificamente no ensino de química, a fim de avaliar a capacidade de tomada de decisão de alunos do Ensino Médio, a partir de um estudo de caso envolvendo questões sociais, econômicas e ambientais relacionadas o desmatamento da vegetação utilizada na produção do artesão daquela região. Os autores concluíram a partir do caso que:

O estudo do artesanato e sua relação com o ensino de ciências possibilitou trabalhar com questões que levam a valorização da cultura local, que muitas vezes é "sufocada" por um padrão que é imposto pela classe dominante. Portanto, a construção de atividades que exaltam a riqueza local e valorizam os saberes/conhecimentos de comunidades tradicionais, devem fazer parte do planejamento curricular. Acreditamos que a resistência dos docentes em criar formas de trabalhar os conteúdos, depende de sua motivação e da sua formação o que pode ser explorado em outros estudos. (SILVA; MELO; MACEDO ARGUELHO, 2020, p.24)

Ainda nesta perspectiva, Wartha, Silva e Berjarano (2013), ao discutir em seu artigo sobre contextualização e cotidiano, afirmam que:

Falar em contextualização, portanto, também requer cuidados dos pesquisadores e professores. Aponta-se que há diversas perspectivas colocadas quando se fala em contextualização: a contextualização não redutiva, a partir do cotidiano; a contextualização a partir da abordagem CTS; e a contextualização a partir de aportes da história e da filosofia das ciências. (WARTHA; SILVA; BERJARANO, 2013, p. 90)

Uma contextualização numa perspectiva para o ensino CTS é aquela em que o aluno sinta-se estimulado e desperte o interesse pelo conteúdo abordado, bem como a busca de novos conhecimentos relacionados à temática discutida em sala, de modo que construa seu próprio conceito e, assim, poder posicionarse frente a um problema real presente no meio em que esteja envolvido, relacionando as questões sociais, políticas e econômicas, bem como o uso de tecnologias e criação de novos produtos.

Corroborando para construção do conceito em questão, Santos e Mortimer (1999) fazem uma diferenciação entre a contextualização do conhecimento científico e o ensino de ciências do cotidiano:

Enquanto a contextualização aborda a ciência no seu contexto social com as suas inter-relações econômicas, ambientais, culturais etc., o 
ensino de ciências do cotidiano trata dos conceitos científicos relacionados aos fenômenos do cotidiano. No segundo caso, a abordagem continua centrada nos conceitos científicos e não necessariamente são explicitadas as relações entre ciência e tecnologia, bem como o desenvolvimento de atitudes e valores em relação à ciência e suas implicações na sociedade. (SANTOS e MORTIMER, 1999, p.6).

O exemplo de contextualização como exemplificação de situações cotidianas é muito encontrado nos livros didáticos de química, os quais abordam, de forma superficial, fatos históricos ou até mesmo quando mencionam um personagem relevante para o conteúdo discutido em questão, buscando relacionar um contexto, a exemplo da forma como são apresentados os modelos atômicos: Dalton, Rutherford, Bohr dentre outros, na qual o conhecimento sobre a ciência é apontado como algo pronto e acabado. :

Nesse sentido, observamos que há diferentes compreensões acerca do conceito de contextualização, e de fato o que seja contextualizar para os professores em sua prática docente. Essa busca pela contextualização do conteúdo e as diferentes interpretações podem ser observadas nos trabalhos realizados por Santos e Mortimer (1999); González (2004) e Silva e Marcondes (2010).

Santos e Mortimer (1999) justificando a escolha de sua pesquisa apontam que:

Temos presenciado o uso do termo contextualização com diferentes significados. Diante do destaque dado ao tema nas Diretrizes Curriculares e da diversidade de significados atribuídos ao termo, consideramos importante investigar o que os professores entendem por contextualização. (SANTOS; MORTIMER, 1999, p. 1)

Dessa forma, buscaram compreender as concepções de professores sobre a temática contextualização social no ensino de química, uma pesquisa realizada com 24 professores de Belo Horizonte e do Distrito Federal, por Santos e Mortimer (1999, p. 1-2) apontaram que:

[...] Após a análise das categorias levantadas, sintetizamos as mesmas em três categorias genéricas: contextualização como estratégia de ensino-aprendizagem para facilitar a aprendizagem; contextualização como descrição científica de fatos e processos do cotidiano do aluno; e contextualização como desenvolvimento de atitudes e valores para a formação de um cidadão crítico. 
As categorias sobre contextualização definidas por Santos e Mortimer (1999) são: 1-Contextualização como estratégia de ensino-aprendizagem para facilitar a aprendizagem: se configura por meio da abordagem do conteúdo químico através da exemplificação e ilustração de fatos cotidianos, não apresentando um enfoque nos problemas sociais e a sua relação com o meio ambiente. 2-Contextualização como descrição científica de fatos e processos do cotidiano do aluno: é entendida através da explicação e/ou descrição de processos físicos e químicos presentes no cotidiano do aluno, apresentando uma relação direta ou indiretamente do conteúdo químico. Ainda nesta categoria discute questões tecnológicas envolvidas nestes processos. 3-Contextualização como desenvolvimento de atitudes e valores para a formação de um cidadão crítico: se discute situações ou problemas reais presentes no cotidiano dos alunos, apresentando uma relação com os aspectos sociais, políticos, econômicos e ambientais, com o intuito de contribuir com a construção de uma postura crítica dos alunos enquanto cidadãos na sociedade onde vivem.

Nessa mesma intenção, González (2004, p. 215) destaca prováveis tipos ou considerações que apontem para a contextualização. Dentre elas, citamos: contextualização histórica, contextualização metodológica e contextualização socioambiental.

1: Contextualização histórica: como uma forma de mostrar como e por que surgem ideias e teorias científicas, se opondo à visão a problemática que costuma aparecer no ensino de Ciências na maioria das vezes. 2: Contextualização Metodológica: como uma forma de influenciar não só nos conteúdos como objetos terminais, mas também nas formas em que isso pode ser gerado. Em oposição à visão dogmática de senso comum que tende a ser oferecida através de uma ciência acabada e préfabricada na qual o aluno é um mero receptor e consumidor. 3: Contextualização Socioambiental: como forma de ver a utilidade da ciência em nosso modo de ver o mundo e de interagir com ele, se opondo à visão teoricista e descontextualizada que concebe a ciência como algo puramente abstrato e sem relação com a realidade que nos rodeia (GONZÁLEZ, 2004, p.215) (tradução nossa).

Entendemos, dessa forma, que há uma complementação nos tipos de abordagens relacionadas à contextualização. Uma depende da outra no processo de ensino-aprendizagem e, a partir desses referenciais, nota-se uma 
semelhança nas descrições dos conceitos de contextualização definidos por estes autores, diante das categorias criadas.

Silva e Marcondes (2010) com o objetivo de investigar as ideias e proposições de um grupo de professores a respeito da contextualização no ensino de química, a fim de entender quais as concepções sobre essa temática frente à formação de novos conceitos, realizaram uma oficina temática por meio de um curso de formação continuada com um grupo de professores atuantes em escolas públicas e particulares do estado de São Paulo.

Estes professores, após várias discussões e leituras sobre a contextualização no ensino de Química com enfoque CTS, elaboraram materiais didáticos instrucionais, especificamente unidades didáticas, os quais manifestaram as suas compreensões sobre contextualização, conforme descreve o recorte a seguir:

\begin{abstract}
Esses materiais didáticos apresentavam as características da contextualização como: exemplificação e curiosidades; descrição científica de fatos e processos; fundamentos CTS e transformação social. Para coleta de dados, nessa etapa, adotou-se um questionário aberto em que se procurava verificar as relações que os professores estabeleciam entre materiais didáticos produzidos por outros professores e as concepções de contextualização apresentadas ao longo do curso. (SILVA; MARCONDES; 2010 p.106).
\end{abstract}

Após a análise dos materiais, observaram que houve uma ampliação das concepções dos professores que caracterizavam inicialmente o ensino de Química contextualizado como simples exemplificação e descrição de fatos ou situações do cotidiano com o intuito de ensinar química, e passaram a compreender ideias de contextualização como a abordagem de questões sociais, com vistas a desenvolver atitudes e valores e à transformação da realidade social.

Sendo assim, acreditamos que contextualizar é construir significados, incorporando valores que explicitem o cotidiano, com uma abordagem social e cultural que facilitem o processo da descoberta. É levar o aluno a entender a importância do conhecimento e aplicá-lo na compreensão dos fatos que o 
cercam. Contribuindo com a nossa visão, Fernandes, Marques e Delizoicov (2016, p.24) apontam que:

[...] é importante ressaltar que a contextualização não se efetiva no vácuo conceitual, havendo a necessidade, assim, de se elaborar um planejamento em que contexto e conceito tenham uma relação não dicotômica. É preciso superar igualmente a concepção de contexto como algo que justifique a inserção de determinada conceituação já selecionada em programas de ensino por critérios, muitas vezes, inerciais.

Pazinato, Souza e Regiani (2019) realizaram uma busca em artigos da Revista Química Nova na escola, com o objetivo de analisar e compreender o que significa um ensino contextualizado em propostas pedagógicas e experiências de ensino, descritas em artigos publicados na Seção Relatos de Sala de Aula. Os autores concluíram quem há diversidade de concepções de contextualização entre diferentes profissionais da Educação em Química, podendo ora ser enriquecedoras para o ensino de Química, ora limitantes para construção de uma visão mais ampla acerca do tema.

Assim, a visão e concepção de contextualização defendida, que se propõe discutir neste trabalho, é aquela em que o aluno possa tornar-se o protagonista no cenário atual na sociedade a qual esteja relacionado aos princípios curriculares, a fim de assumir um compromisso tanto do desenvolvimento de tomada de decisão dos alunos numa perspectiva crítica e não apenas a mera ilustração ou exemplificação do cotidiano (SANTOS, 2007).

Neste contexto Wartha, Silva e Berjarano (2013, p. 90) apontam que:

[...] as possibilidades de mediações didáticas que o professor poderá encontrar a partir das diferentes concepções de contextualização do ensino podem ser muitas, sendo estas apenas algumas delas. O importante é o professor estar atento a elas, para que ele possa assumir, de fato, o seu papel de mediador (ativo) dos processos de ensino e aprendizagem.

Em suma, além de ocorrer diferentes concepções do que seja contextualização do conhecimento científico por parte de professores, discutimos que uma das possibilidades para diferentes interpretações do conceito de contextualização está no fato das diferentes possibilidades de 
interpretação daquilo que se lê. Isso porque, podemos ler uma mesma palavra ou expressão e apresentar sentidos e significados diferentes para cada pessoa.

[...] precisamos ter presente a relação entre leitura e significação. Se um texto pode ser considerado objetivo em seus significantes, não o é nunca em seus significados. Todo texto possibilita uma multiplicidade de leituras, leituras essas, tanto em função das intenções dos autores como dos referenciais teóricos dos leitores e dos campos semânticos em que se inserem (MORAES, 2003, p.192).

O significado da leitura será a partir da vivência de cada ser humano, e da aquisição de informações e conhecimentos construídos ao longo da vida. A interpretação do que se lê, está diretamente relacionada ao contexto social, cultural e material dentro da sociedade que está inserido. E isso mostra que a leitura e a significação estão inteiramente relacionadas, porém nem sempre terá o mesmo significado para cada indivíduo.

[...] toda leitura já é uma interpretação e que não existe uma leitura única e objetiva. Ainda que, seguidamente dentro de determinados grupos, possam ocorrer interpretações semelhantes, um texto sempre possibilita múltiplas significações. Diferentes sentidos podem ser lidos em um mesmo texto (MORAES, 2003, p.192-193).

\section{METODOLOGIA DE PESQUISA}

Realizamos uma intervenção e mediação de leitura com a utilização de dois artigos que discutem a contextualização no ensino de Ciências numa perspectiva com enfoque CTS. A atividade foi desenvolvida com um grupo de 19 licenciandos de uma Universidade Federal do Nordeste, durante a realização do Estágio Supervisionado em Química. Apegamo-nos em avaliar os discursos escritos dos licenciandos sobre a contextualização, a partir dos estudos, realizados por eles e mediados pelo professor formador, sobre as ideias de Santos (2007; 2008); Santos et al (2010). As análises dos dados e discursos escritos foram feitas, tendo como referencial a Análise Textual Discursiva (ATD) (MORAES, 2003; MORAES; GALIAZZI, 2011). 
Para os autores a ATD pode ser compreendida como um processo autoorganizado de construção de novos significados em relação a determinados objetos de estudo, a partir de materiais textuais referentes a esses fenômenos.

\begin{abstract}
A análise textual propõe-se a descrever e interpretar alguns dos sentidos que a leitura de um conjunto de textos pode suscitar. Sempre parte do pressuposto de que, toda leitura já é uma interpretação e que não existe uma leitura única e objetiva. [...] os textos são assumidos como significantes em relação aos quais é possível exprimir sentidos simbólicos. Pretende-se construir compreensões a partir de um conjunto de textos, analisando-os e expressando a partir dessa investigação alguns dos sentidos e significados que possibilitam ler. Os resultados obtidos dependem tanto dos autores dos textos quanto do pesquisador. (MORAES e GALIAZZI, 2011, p. 14).
\end{abstract}

Compreendemos a necessidade da criação de categorias emergentes, advindas das produções textuais dos licenciandos, de acordo com as etapas da ATD proposta por Moraes e Galiazzi (2011 p. 11-12).

1- Desmontagem dos textos: esta etapa é considerada como processo de unitarização. Implica examinar os textos em seus detalhes, fragmentando-os no sentido de atingir unidades constituintes, enunciados referentes aos fenômenos estudados (MORAES e GALIAZZI, 2011). Nesta etapa, os textos produzidos e os discursos dos licenciandos foram transcritos, em seguida, foram retirados fragmentos compostos por enunciados e terminologias relacionadas ao conceito de contextualização.

2- Estabelecimento de relações: este processo é denominado de categorização. Consiste em construir relações entre unidades de base, combinando e classificando-os, reunindo esses elementos próximos, resultando daí sistemas de categorias (MORAES e GALIAZZI, 2011). Nesta etapa, os textos e discursos foram analisados, sendo, portanto, enquadrados quando apresentam aproximações e semelhanças entre si, considerando os recortes e expressões com sentidos.

3- Captando o novo emergente: a análise desencadeada dos processos anteriores possibilita a emergência de uma compreensão renovada do todo. $O$ investimento na comunicação dessa nova compreensão, assim como o de sua crítica e validação, constitui o último elemento do ciclo de análise proposto. $O$ metatexto resultante desse processo representa um esforço de explicar a compreensão que se apresenta como produto de uma nova combinação dos 
elementos construídos ao longo dos passos anteriores (MORAES e GALIAZZI, 2011 ). Nesta etapa, foram criadas as categorias a partir da leitura dos artigos teóricos, os quais serviram para comparar com as categorias que emergiram das produções textuais dos licenciandos, a fim de identificar as aproximações deles com o conceito relevante discutido e defendido pelo autor.

4- Um processo auto-organizado: o ciclo de análise, ainda que composto de elementos racionalizados e em certa medida planejados em seu todo, pode ser compreendido como um processo auto-organizado do qual emergem novas compreensões. Os resultados finais, criativos e originais, não podem ser previstos. Mesmo assim, é essencial o esforço de preparação e impregnação para que a emergência do novo possa concretizar-se (MORAES e GALIAZZI, 2011). Nesta etapa, comparamos a produção textual em grupos, uma vez que os discursos foram organizados de acordo com as categorias a princípio criadas. Partindo da ideia de que, a partir das leituras teóricas, é possível admitir a concretização ou compreensão de uma teoria.

O processo de leitura e interpretação torna-se necessário na formação do leitor, pois expressam uma multiplicidade de sentidos que são construídos ao longo da vida do indivíduo, diante das teorias e significados que são atribuídos em diferentes momentos no exercício prático da leitura. Essa diversidade de sentidos também determina diferentes focos de análise que, no entendimento, requer uma leitura aprofundada do texto.

\footnotetext{
Exercitar uma leitura aprofundada é explorar uma diversidade de significados que podem ser construídos com base em um conjunto de significantes. É ainda explorar significados em diferentes perspectivas, valendo-se de diferentes focos de análise. Essa diversidade de sentidos que podem ser construídos a partir de um conjunto de textos está estreitamente ligada às teorias que os leitores utilizam em suas interpretações textuais. Por mais sentidos que se consiga mostrar, sempre haverá mais sentidos. (MORAES, 2003, p.196).
}

A mediação da leitura foi feita da seguinte forma: os licenciandos faziam a leitura dos dois artigos, o professor formador esclarecia as incompreensões apontadas por eles, sempre buscando uma reflexão através de questionamentos. 
Em seguida, os licenciandos produziam um texto referente ao assunto discutido nos mesmos, a fim de apontar as suas compreensões sobre a leitura e análise.

Conforme orienta Galiazzi (2011) essa leitura:

[...] é feita a partir de alguma perspectiva teórica, seja esta consciente ou não. Ainda que se possa admitir o esforço em pôr entre parênteses essas teorias, qualquer leitura implica ou exige algum tipo de teoria para poder concretizar-se. É impossível vê sem teorias, é impossivel ler e interpretar sem ela. (MORAES; GALIAZZI, 2011, p.15).

A nossa intenção não foi avaliar se a leitura estava certa ou errada, mas sim - que os licenciandos entenderam ou interpretaram dos artigos lidos a partir da produção de um texto. A interpretação nesse contexto está diretamente relacionada à história de vida de cada participante. Para tanto, Moraes (2003, p. 204) aponta que:

Descrever nesse sentido constitui-se num movimento de produção textual mais próximo do empírico, sem envolver um exercício de afastamento interpretativo mais aprofundado. Desse modo, a descrição se constitui em exposição de ideias de uma perspectiva próxima de uma leitura imediata, mesmo que aprofundada. Entretanto, na medida em que nos afastamos dessa realidade mais imediata do texto, estamos nos envolvendo gradativamente mais num exercício aqui denominado interpretativo.

Para evidenciar a proposta dos autores dos artigos utilizados na pesquisa, selecionamos o resumo presente em cada um deles.

Resumo artigo 1: Educação Científica Humanística em uma Perspectiva Freireana: Resgatando a Função do Ensino de CTS (Santos 2008).

O movimento de ensino de ciências com enfoque CTS surgiu com uma forte tendência de crítica ao modelo econômico desenvolvimentista, todavia o seu discurso foi incorporado em outros contextos, que levou ao aparecimento de muitas propostas de ensino que acabam por reforçar uma visão reducionista de CTS. A partir da concepção humanística de educação de Paulo Freire são discutidos princípios a ser incorporados ao ensino de CTS, visando resgatar o caráter político dessa abordagem educacional. Considerando concepções de diferentes modelos curriculares de CTS são apresentadas congruências e divergências desse ensino com a perspectiva freireana e discutidos modelos curriculares com essa perspectiva. Propõem-se assim a inclusão de aspectos sociocientíficos ao currículo que seja abordado no sentido de desvelar o contexto de exploração da sociedade científica e tecnológica que amplie a visão reducionista de muitas propostas de CTS para a construção de uma educação humanística com uma perspectiva freireana. (SANTOS, 2008, p.109) 
Resumo artigo 2: Contextualização no ensino de ciências por meio de temas CTS em uma perspectiva crítica (Santos 2007).

\begin{abstract}
No presente artigo, partindo-se do movimento ciência-tecnologiasociedade - CTS ou ciência-tecnologia-sociedade-ambiente - CTSA, propõe-se uma abordagem de contextualização no ensino de ciências em uma perspectiva crítica, apresentando como exemplo o modelo curricular desenvolvido pelo Projeto de Ensino Químico e Sociedade - Pequis na Universidade de Brasília. Para isso, são discutidas concepções de contextualização de CTS e orientações curriculares estabelecidas pelos documentos dos Parâmetros Curriculares Nacionais - PCN. A partir dessas considerações, são delineadas questões sobre o que seria um ensino de CTS/CTSA na perspectiva crítico-social, incorporando ideias de Paulo Freire. Ao final, são apresentadas sugestões de abordagem dessa perspectiva e desafios a serem enfrentados pelos professores (SANTOS, 2007, p.1).
\end{abstract}

\title{
RESULTADOS E DISCUSSÕES
}

A partir da análise dos discursos presentes nas produções textuais dos licenciandos (LIC), feitos após leitura e discussão com o professor formador dos artigos, foi possível perceber três categorias emergentes:

a) Contextualização com a compreensão de valores humanísticos: dez licenciandos destacaram, em sua produção textual, a importância dos valores humanísticos apontados nos artigos. As unidades de análise obtidas da unitarização das produções textuais de LIC 10 e LIC 18 demonstram como emergiv esta categoria.

Observa-se que os licenciandos entendem as relações e interrelações existentes no ensino CTS, a partir de temas como um caminho para formar cidadãos críticos na sociedade. Essa observação pode ser vista nos recortes a seguir:

LIC 10: "Com o conhecimento do ensino CTS, fica visível que não basta aprender ciência pela ciência, mas, sim, dar significados e valores para que se possa ter uma aprendizagem significativa, uma vez que, o ensino CTS busca desenvolver valores éticos, políticos e sociocultural através da contextualização do ensino".

LIC 18: "Essa contextualização, em volta dos temas de ciência, tecnologia e sociedade, forma um cidadão crítico, que possa dar opiniões dentro da 
sociedade em que vive, a partir do conteúdo que ele aprende dentro da sala de aula".

Observa-se que este grupo de licenciandos apresenta o ensino CTS como possibilidade de conhecimento científico para que possa julgar criticamente o que é bom ou ruim na sociedade e dar opiniões, a fim de promover a tomada de decisão, sobretudo aponta valores humanísticos para formação do cidadão. Esses valores estão relacionados com a formação do indivíduo frente a sua postura ética e igualitária, buscando a justiça social, a equidade e uma forma consciente e crítica de interpretar a realidade que o cerca.

Os valores humanistícos apontados em estudos da inserção da perspectiva educacional CTS estão relacionados com:

[...] interesses coletivos, como os de solidariedade, de fraternidade, de consciência do compromisso social, de reciprocidade, de respeito ao próximo e de generosidade. Tais valores, na perspectiva desses movimentos, se relacionam às necessidades humanas, em uma perspectiva de questionamento à ordem capitalista, na qual os valores econômicos se impõem aos demais. (SANTOS, 2007, p. 7).

Na perspectiva da ATD é perceptível que este grupo de licenciandos, manifestou interesse em destacar os valores humanísticos que receberam ou o que lhes faltaram ao longo das leituras e dos conhecimentos teóricos adquiridos até este momento da vida. Neste caso, os elementos de significados compreendidos pelos participantes foram os valores humanísticos implícitos na perspectiva de ensino CTS.

b) Contextulização com a compreensão dos problemas socioambientais: três licenciandos destacaram uma valorização das questões socioambientais contempladas nos artigos, como pode ser percebido no recorte do discurso escrito do LIC 03:

LIC 03: "O movimento da ciência-tecnologia-sociedade (CTS) tem como abordagem uma contextualização no ensino de ciências, fazendo com que possa refletir criticamente sobre os assuntos abordados, incorporando novos currículos no ensino de ciências, propondo incorporar conteúdos de ciências-tecnologia-sociedade-ambiental, que é CTSA, promovendo a ênfase nas questões ambientais, buscando a educação ambiental". 
LIC 05: "Contextualização é inserir um tema social relevante dentro do cotidiano do aluno ou sociedade. Uma abordagem explicando a importância do conteúdo, a utilidade, o uso correto, o problema que pode causar quando utilizado de forma inadequada ao ser humano e ao meio ambiente, a sustentabilidade [...]".

Analisando os discursos deste grupo, observa-se que os licenciandos conseguiram entender a proposta do texto, no sentido de discutir a contextualização numa perspectiva crítica de conceitos socioambientais. Observamos, portanto, que os discursos são dotados de muitas expressões e terminologias que foram retiradas na íntegra do artigo analisado, com a tentativa de dar um sentido à leitura realizada por eles. Considerando a ATD, é notável que este pequeno grupo apontou como significantes do texto os problemas sociais e ambientais, os quais podem ser aprendidos a partir da perspectiva educacional CTS.

Contribuindo para esta análise, a visão de Santos (2007) sobre os objetivos centrais da contextualização na perspectiva CTS no ensino de ciências, pode ser vista no recorte a seguir:

[...] a contextualização pode ser vista com os seguintes objetivos: 1) desenvolver atitudes e valores em uma perspectiva humanística diante das questões sociais relativas à ciência e à tecnologia; 2) auxiliar na aprendizagem de conceitos científicos e de aspectos relativos à natureza da ciência; e 3) encorajar os alunos a relacionar suas experiências escolares em ciências com problemas do cotidiano. (SANTOS, 2007, p.5).

\section{c) Contextualização com entendimento da perspectiva educacional CTS}

- aqui, seis licenciandos buscaram, na sua produção textual, a compreensão do movimento CTS na educação, já que seus discursos escritos eram dotados de muitas expressões e terminologias que foram retiradas na íntegra do artigo analisado, na tentativa de dar um sentido à leitura realizada por eles, conforme pode ser visto nos recortes do LIC 04 e LIC 06:

LIC 04: "O movimento CTS surgiu na década de 1970, com o objetivo de correlacionar as questões envolvendo três eixos: ciência, tecnologia e sociedade. No Brasil, as inovações na área de ensino de Ciências surgiram 
na década de 1950, porém foi apenas na década de 1990 que os currículos começaram a fazer menção às ideias CTS".

LIC 06: "O artigo discute basicamente o ensino CTS e CTSA, que ao se preocupar também com a educação ambiental, o enfoque (ensino) sobre ciência, tecnologia e sociedade inclui a palavra ambiente [...]"

O discurso do LIC 04 aponta a origem do movimento CTS e menciona quando os currículos iniciaram as discussões sobre a temática, porém, não deixa fica claro o objetivo central do movimento CTS e suas implicações na sociedade. Na escrita de LIC 06 ocorre uma mera reprodução e compreensão de um fragmento do texto lido. Entendemos que este grupo de licenciandos se preocupa em entender o conceito defendido pelo autor, quanto à contextualização numa perspectiva crítica (SANTOS, 2007) e apontam uma visão simplista e fragmentada sobre a contextualização como mera reprodução e menção do que se ler.

Essa mesma análise é apontada por Santos (2007) quando diz:

Para muitos, a simples menção do cotidiano já significa contextualização[...] Muitas vezes, essa aparente contextualização é colocada apenas como um pano de fundo para encobrir a abstração excessiva de um ensino puramente conceitual enciclopédico de cultura de almanaque. Nessa visão, são adicionados cada vez mais conteúdos ao currículo, como se o conhecimento isolado por si só, fosse a condição de preparar os estudantes para a vida social. (SANTOS, 2007, p.4- 5).

Ainda neste contexto, Freire (2001) destaca que a leitura e a escrita estão associados às formas de expressão do educando, buscando compreender a sua prática social de maneira correta. Esta dificuldade também foi identificada por Francisco Junior (2010) ao propor a leitura de artigos seguidos da produção textual, conforme o recorte a seguir:

Além de interagir, no entanto, o leitor precisa agir sobre o texto para poder interagir. Entretanto, essa é outra atividade que os estudantes, em geral, demonstram dificuldades. Em boa parte dos casos, os trechos são apenas destacados, sem a emissão de comentários ou de opiniões. Muitos estudantes argumentam que acham o trecho importante, mas não conseguem refletir por escrito. (FRANCISCO JUNIOR, 2010, p. 224) 
Francisco Junior (2010) corrobora com este resultado e avaliação da mediação, apontando que o papel da leitura é irrevogável na formação do educador e que estratégias de leituras devem ser fomentadas na formação destes, até que haja uma melhoria contínua da comunicação entre a linguagem escrita e da reflexão crítica do leitor professor.

[...] a organização pedagógica da leitura, função do educador, tem papel irrevogável. Essa organização deve fomentar o desenvolvimento de recursos que facilitem os educandos a assumirem a dialogicidade necessária frente ao texto. Insistir e, acima de tudo, orientar os estudantes a argumentarem sobre a leitura do texto, promove, gradativamente, a aquisição de posicionamentos pessoais e críticos. À medida que essas atividades forem propaladas e propagadas em diferentes disciplinas e, quiçá, por diferentes professores, poder-se-ão promover qualidades como a capacidade de comunicação, análise e reflexão crítica, argumentação, entre outras, cada vez em maior grau. (FRANCISCO JUNIOR, 2010, p.225)

\section{CONDIDERAÇÕES FINAIS}

Através do estudo realizado sobre as manifestações interpretativas sobre contextualização crítica numa perspectiva de ensino CTS, com os licenciandos em Química de uma universidade pública do Nordeste, identificou-se que, grande parte destes, apresentou uma interpretação simplista do conceito de contextualização crítica com enfoque CTS, defendido pelo Wildson Luiz Pereira dos Santos, estudado como referencial teórico e de investigação, mediante análise e leitura dos artigos: Educação Científica Humanística em uma Perspectiva Freireana: Resgatando a Função do Ensino de CTS (Santos, 2008) e Contextualização no ensino de ciências por meio de temas CTS em uma perspectiva crítica (Santos 2007).

A discussão da temática foi fundamentada na Análise Textual Discursiva ATD proposta por Moraes e Galiazzi (2011). Esta mediação apontou para o surgimento de categorias emergentes, as quais foram criadas por meio do discurso do referencial teórico dos textos, considerando as indicações principais sobre o conceito de contextualização numa perspectiva crítica, as aproximações e as complementações dos mesmos, o que permitiu a categorização do discurso sobre vários tipos de contextualização. 
As categorias emergentes foram: a) Contextualização com a compreensão de valores humanísticos; b) Contextulização com a compreensão dos problemas socioambientais; c) Contextualização com entendimento da perspectiva educacional CTS. A partir das produções textuais dos licenciandos, foi possível identificar concepções emergentes e enquadrar os discursos dos licenciandos, contribuiu para um avanço ainda muito tímido na formação destes, houve diferentes interpretações, não apenas por falta de compreensão por parte dos licenciandos em química, mas diante da formação familiar e profissional que receberam.

Retomamos, neste sentido, a atribuição de que a dificuldade dos licenciandos em ler e compreender os artigos analisados está relacionada com o modelo tradicional de ensino transmissivo-receptivo, impregnado no discurso de muitos professores nas universidades, os quais são transmitidos aos alunos, que memorizam e reproduzem o que se lê, além disso, deve-se considerar o que lhes falta e o que foi de interesse por parte deles em destacar a partir dos momentos de leitura que tiveram.

Ademais, através dos discursos analisados, percebemos que houve uma tensão da parte deles em tentar definir de forma relevante o conceito de contextualização crítica, buscando de alguma maneira alcançar o discurso do autor, frente aos conteúdos químicos a serem ministrados em sala de aula, relacionando as questões sociais ao cotidiano, aparentando que este conceito está impregnado do contexto no qual estes licenciandos estão inseridos, em especial, a sala de aula na universidade, sobretudo, a participação em encontros, palestras e atividades realizadas de outras disciplinas durante o processo de formação.

Acreditamos que a realização deste trabalho fomenta uma discussão mais complexa para a realização de novas pesquisas com essa questão e análise, possibilitando o acompanhamento dos sujeitos da pesquisa em outros momentos de sua formação, ou seja, nos períodos adiante, a fim de avaliar o discurso de forma contínua, pois julgamos que estas concepções ainda sofrerão evoluções frente ao que foi discutido até aqui. Além disso, fomentar possibilidades e estratégias de leitura com momentos de discussão e análise crítica, não só com 
licenciandos em química, mas de áreas correlatas ao ensino de Ciências, em todos os níveis de ensino.

\section{REFERÊNCIAS}

BRASIL, Ministério da Educação. Secretaria de Educação Média e Tecnológica. Parâmetros Curriculares Nacionais. Ensino Médio: Ciências da Natureza, Matemática e suas Tecnologias. Brasília: MEC, 1999.

BRASIL, Ministério da Educação. Secretaria de Educação Média e Tecnológica. Parâmetros Curriculares Nacionais. Ensino Médio: Ciências da Natureza, Matemática e suas Tecnologias. Brasília: MEC, 2002.

COSTA-BEBER, Laís Basso; Maldaner, Otávio Aloísio. Cotidiano e Contextualização na Educação Química: discursos diferentes, significados próximos. In: Atas ENPECEncontro Nacional de Pesquisa em Educação em Ciências; Campinas-SP; 2011.

FERREIRA, M. C. S.; JÚNIOR, M. B. A importância do projeto político pedagógico na construção do processo de ensino-aprendizagem contextualizado: um estudo de caso da CEFFA Manoel Monteiro. Revista Exitus, v. 10, p.02001 1, 2020.

FERNANDES, C. S.; MARQUES, C. A.; DELIZOICOV, D. Contextualização na formação inicial de professores de ciências e a perspectiva educacional de Paulo Freire. Ensaio Pesquisa em Educação em Ciências (Belo Horizonte), v. 18, n. 2, p. 9-28, 2016.

FRANCISCO JUNIOR, Wilmo Ernesto. Estratégias de leitura e educação química: que relações. Química Nova na Escola, v.32, n.4, p.220-226, 2010.

FREIRE, Paulo. Educação como prática da liberdade. Rio de Janeiro, Paz e Terra, 1999.

FREIRE, Paulo. Pedagogia da autonomia: saberes necessários à prática educativa. São Paulo, Paz e Terra, 1997.

FREIRE, Paulo. Pedagogia da esperança. Rio de Janeiro, Paz e Terra, 1992.

GONZÁLEZ, C. V. Reflexiones y Ejemplos de Situaciones Didácticas para una Adecuada Contextualización de los Contenidos Científicos en el Proceso de Enseñanza. Revista Eureka sobre Enseñanza y Divulgación de las Ciencias.v.1, n. 3, 2004.

LOPES, Alice Casimiro. Os parâmetros curriculares nacionais para o ensino médio e a submissão ao mundo produtivo: o caso do conceito de contextualização.

Educação \& Sociedade, v23, n.80, p.386-400, 2002. 
MORAES, Roque. Uma tempestade de luz: a compreensão possibilitada pela análise textual discursiva. Ciência \& Educação, v.9, n2, p.191-221, 2003.

MORAES, Roque; GALIAZZI, Maria do Carmo. Análise Textual Discursiva. $2^{a}$ edição revisada, Unijuí (Coleção Educação em Ciências), Unijuí, 2011.

PAZINATO, Viviane Lopes; SOUZA, Franciele Drews; REGIANI, Anelise Maria. A contextualização do ensino de química em artigos da revista Químicac Nova na Escola. Scientia Naturalis, v. 1, n. 2, 2019.

RICARDO, Elio Carlos; ZYLBERSZTAJN, Arden. Os Parâmetros Curriculares Nacionais na formação inicial dos professores das Ciências da Natureza e Matemática do ensino médio. Investigações em ensino de ciências, v. 12, n. 3, p.339-355, 2007.

RICARDO, Elio Carlos. Competências, Interdisciplinaridade e Contextualização: dos Parâmetros Curriculares Nacionais a uma compreensão para o ensino das ciências. Tese de Doutorado em Educação Científica e Tecnológica. Universidade Federal de Santa Catarina, Florianópolis-SC, 2005.

SANTOS, Wildson Luis Pereira. Educação científica na perspectiva de letramento como prática social: funções, princípios e desafios. Revista Brasileira de Educação, v. 12, p. 474-492, 2007.

SANTOS, Wildson Luis Pereira.; MORTIMER, Eduardo Fleury. Concepções de Professores sobre Contextualização Social do Ensino de Química e ciências. In:

Reunião Anual da Sociedade Brasileira de Química, 22, 1999, Poços de Caldas, MG. Livro de resumos. São Paulo: Sociedade Brasileira de Química, 1999.

SANTOS, Wildson Luis Pereira; MORTIMER, Eduardo Fleury. A dimensão social do ensino de química - um estudo exploratório da visão de professores. In: Atas II

ENCONTRO NACIONAL DE PESQUISA EM EDUCAÇÃO EM CIÊNCIAS, Valinhos- São Paulo, 1999.

SANTOS, Wildson Luiz Pereira. Contextualização no ensino de ciências por meio de temas CTS em uma perspectiva crítica. Ciência \& Ensino, INSS 1980-8631, v. 1, 2008.

SANTOS, Wildson Luiz Pereira. Educação científica humanística em uma perspectiva Freireana: resgatando a função do ensino de CTS. Alexandria Revista de Educação em Ciência e Tecnologia, v.1, n. 1, p. 109-131, 2008.

SILVA, Erivanildo Lopes da; MARCONDES, Maria Eunice Ribeiro. Visões de contextualização de professores de química na elaboração de seus próprios materiais didáticos. Ensaio Pesquisa em Educação em Ciências, v. 12, n. 1, 2010.

SILVA, J. R. da.; MELO, M. R.; MACEDO ARGUELHO, M. L. P. Apresentando o artenasato como tema social para ensinar ciências/química por uma 
perspectiviva freireana. Revista Exitus, v. 10, p.020019, 2020.

WARTHA, Edson José; ALÁRIO, Adelaide F. A contextualização no ensino de Química através do livro didático. Química Nova na Escola, n²2, p. 42-47, Nov., 2005.

WARTHA, Edson José; SILVA, Erivanildo Lopes; BERJARANO, Nelson Rui Ribas. Cotidiano e contextualização no ensino de Química. Química Nova na Escola, v. 35, n.1, p.84-91, 2013.

Recebido em: 05 de maio de 2020 Aprovado em: 24 de setembro de 2020 Publicado em: 04 de novembro de 2020 